\title{
Hearing loss-familial salivary gland insensitivity to aldosterone syndrome
}

INSERM

\section{Source}

INSERM. (1999). Orphanet: an online rare disease and orphan drug data base. Hearing loss-familial salivary gland insensitivity to aldosterone syndrome. ORPHA:3225

Hearing loss-familial salivary gland insensitivity to aldosterone syndrome is characterised by bilateral moderate-to-severe sensorineural hearing loss and salivary gland insensitivity to aldosterone resulting in hyponatremia. It has been described in two brothers.

Transmission appeared to be autosomal recessive. 